\title{
Metabolic acetate therapy improves phenotype in the tremor rat model of Canavan disease
}

\author{
Peethambaran Arun • Chikkathur N. Madhavarao • John R. Moffett • \\ Kristen Hamilton • Neil E. Grunberg • Prasanth S. Ariyannur • William A. Gahl • \\ Yair Anikster • Steven Mog • William C. Hallows • John M. Denu • \\ Aryan M. A. Namboodiri
}

Received: 15 December 2009/Revised: 9 March 2010 / Accepted: 31 March 2010/Published online: 13 May 2010

(C) The Author(s) 2010. This article is published with open access at Springerlink.com

\begin{abstract}
Genetic mutations that severely diminish the activity of aspartoacylase (ASPA) result in the fatal brain dysmyelinating disorder, Canavan disease. There is no effective treatment. ASPA produces free acetate from the concentrated brain metabolite, $N$-acetylaspartate (NAA). Because acetyl coenzyme A is a key building block for lipid synthesis, we postulated that the inability to catabolize NAA leads to a brain acetate deficiency during a critical period of CNS development, impairing myelination and possibly other aspects of brain development. We tested the hypothesis that acetate supplementation during postnatal
\end{abstract}

Communicated by: K. Michael Gibson

Competing interest: None declared.

Peethambaran Arun, Chikkathur N. Madhavarao, and John R. Moffett have contributed equally.

P. Arun · C. N. Madhavarao 'J. R. Moffett ' P. S. Ariyannur

A. M. A. Namboodiri $(\triangle)$

Department of Anatomy, Physiology and Genetics,

Neuroscience Program and Molecular and Cell Biology Program,

Uniformed Services University of the Health Sciences,

Building C, 4301 Jones Bridge Rd.,

Bethesda, MD 20814, USA

e-mail: anamboodiri@usuhs.mil

K. Hamilton $\cdot$ N. E. Grunberg

Department of Medical and Clinical Psychology

and Neuroscience Program,

Uniformed Services University of the Health Sciences,

4301 Jones Bridge Rd.,

Bethesda, MD 20814, USA

W. A. Gahl

National Human Genome Research Institute, $\mathrm{NIH}$,

Bethesda, MD 20892, USA myelination would ameliorate the severe phenotype associated with ASPA deficiency using the tremor rat model of Canavan disease. Glyceryltriacetate (GTA) was administered orally to tremor rats starting 7 days after birth, and was continued in food and water after weaning. Motor function, myelin lipids, and brain vacuolation were analyzed in GTA-treated and untreated tremor rats. Significant improvements were observed in motor performance and myelin galactocerebroside content in tremor rats treated with GTA. Further, brain vacuolation was modestly reduced, and these reductions were positively correlated

Y. Anikster

Metabolic Disease Unit, Sheba Medical Center,

Tel Aviv, Israel

S. Mog

Division of Comparative Pathology,

Armed Forces Radiobiology Research Institute, Bethesda, MD 20889, USA

W. C. Hallows $\cdot$ J. M. Denu

Department of Biomolecular Chemistry,

School of Medicine and Public Health,

University of Wisconsin,

Madison, WI 53706, USA 
with improved motor performance. We also examined the expression of the acetyl coenzyme A synthesizing enzyme acetyl coenzyme A synthase 1 and found upregulation of expression in tremor rats, with a return to near normal expression levels in GTA-treated tremor rats. These results confirm the critical role played by NAA-derived acetate in brain myelination and development, and demonstrate the potential usefulness of acetate therapy for the treatment of Canavan disease.

\section{Abbreviations \\ AceCS1 Acetyl coenzyme A synthase type 1 \\ ASPA Aspartoacylase \\ GTA Glyceryltriacetate \\ NAA $\quad N$-acetylaspartate}

\section{Introduction}

Canavan disease is an autosomal genetic disorder that results in progressive leukodystrophy, paralysis, and death, usually between 3 and 10 years of age. Currently, there is no effective treatment for this fatal disorder. Canavan disease is caused by mutations in the gene that codes for the enzyme aspartoacylase (ASPA; EC 3.5.1.15) (Matalon et al. 1988). ASPA deacetylates the highly concentrated nervous system-specific molecule, $\mathrm{N}$ acetylaspartate (NAA). The primary metabolic effects of mutations in the gene for ASPA in Canavan disease patients are a lack of NAA deacetylation leading to buildup of NAA in the brain (Kvittingen et al. 1986), decreased brain acetate levels and impaired myelin lipid synthesis (Madhavarao et al. 2005), and greatly increased excretion of NAA in urine. Two hypotheses have been put forward concerning the etiology of Canavan disease (reviewed in Moffett et al. 2007), which suggest disparate treatment strategies.

One treatment strategy is predicated on the hypothesis that NAA is an osmolyte involved in the active regulation of neuronal water balance (Baslow 1999). In this hypothesis, the lack of ASPA activity leads to an inability to control osmolarity in axons, resulting in damage to myelin sheaths and a progressive leukodystrophy (Baslow 2003). Treatment for Canavan disease under this hypothesis has focused on ASPA gene transfer to reduce brain NAA levels (Janson et al. 2002; Leone et al. 2000). To date, ASPA gene transfer therapy has not proven successful in improving motor functions. Based on findings that NAA-derived acetate is responsible for as much as $1 / 3$ of the lipid synthesis that occurs during postnatal myelination, we have proposed that metabolic therapy using acetate supplemen- tation during postnatal myelination might be an effective treatment for Canavan disease (Madhavarao et al. 2004, 2005). Glyceryltriacetate (GTA), the acetate triester of glycerol, was used for acetate supplementation in the current study because it is well tolerated when given orally (Madhavarao et al. 2009) and intravenously (Bailey et al. 1991, 1992), and is distributed to the brain rapidly due to its hydrophobic nature (Mathew et al. 2005).

The current studies examine the use of GTA as a metabolic treatment for ASPA deficiency using the tremor rat model of Canavan disease. These animals develop a spongy degeneration of the brain, as is the case with ASPA (-/-) knockout mice and Canavan disease patients. The tremor rat model has been used previously for both gene transfer therapy experiments (Klugmann et al. 2005; McPhee et al. 2005) and myelin lipid analyses (Wang et al. 2009). We bred homozygous, ASPA-deficient tremor rats from heterozygous adults, and treated them with orally administered GTA. Here, we report on the phenotypic improvements in motor function, myelin galactocerebroside content, and brain vacuolation observed in GTA-treated tremor rats as compared with those who were untreated. Both NAA-derived acetate and GTA-derived acetate must be converted to acetyl coenzyme A before the acetate can be utilized for metabolic reactions such as lipid synthesis. We therefore examined acetyl coenzyme A synthase type 1 (AceCS1) expression in 18-day-old wild-type rats, and in untreated and GTA-treated tremor rats to determine the cellular localization of this enzyme during myelination and in response to GTA treatment.

\section{Materials and methods}

\section{Tremor rat breeding}

All the procedures were performed in accordance with guidelines of the National Institutes of Health and the Institutional Animal Care and Use Committee. Pairs of breeder heterozygote tremor rats were supplied by the National Bio Resource Project for the Rat in Japan, Kyoto University (Kyoto, Japan). ASPA-null tremor rats $(\mathrm{tm} / \mathrm{tm})$ were bred from heterozygous adults $(\mathrm{tm} /+)$, and identified tentatively based on their appearance at birth. Tremor rat pups could be distinguished from wild-type pups based on the presence of curled vibrissae. PCR analyses were used to confirm the genotype of tremor rats. PCR was performed on rat tail tissue digests (Direct PCR kit; Viagen Biotech, Los Angeles, CA) using primers 5'-TTCAACAGAGGAAT GGATACAGAAA and 5'- CACTCCATGCTTCCTTTT CAACAGC (Kitada et al. 2000) at an annealing temperature of $55^{\circ} \mathrm{C}$, and $\mathrm{Mg}^{++}$concentration of $1.5 \mathrm{mM}$ using a commercial kit (New England Biolabs, Ipswich, MA). 
Peroxidase immunohistochemistry

ASPA immunohistochemistry was used to confirm the ASPA-deficient phenotype of homozygous tremor rats. The ASPA antibodies were generated against an 18 amino acid sequence from human ASPA as previously described (Hershfield et al. 2006). In addition, immunohistochemistry was done with rabbit polyclonal antibodies to the enzyme acetyl coenzyme A synthase-1 (AceCS1) in order to determine if this enzyme was present in oligodendrocytes during postnatal myelination, and if it was expressed in the tremor rat brain. Rabbit polyclonal antibodies were generated against purified, recombinant AceCS1 protein (Hallows et al. 2006), and have been described previously (Ariyannur et al. 2010). Five wild-type Wistar rats, 3 untreated tremor rats, and 2 GTA-treated tremor rats (Kyoto Wistar strain, 160-250 g, bred in our facility) were anesthetized with pentobarbital $(100 \mathrm{mg} / \mathrm{kg})$ and perfused transcardially with $400 \mathrm{ml}$ of $4 \%$ freshly depolymerized paraformaldehyde. Two 18-day-old Sprague Dawley rats were anesthetized with pentobarbital $(100 \mathrm{mg} / \mathrm{kg})$ and perfused transcardially with $200 \mathrm{ml}$ of $4 \%$ freshly depolymerized paraformaldehyde. Brains were removed and postfixed for 3-6 h in paraformaldehyde before being passed through a series of 10,20 , and $30 \%$ sucrose solutions. Brains were sectioned at a thickness of $20 \mu \mathrm{m}$ at $-17^{\circ} \mathrm{C}$ and tissue slices were collected in PBS.

Avidin-biotin complex/peroxidase immunohistochemistry was done as previously described (Ariyannur et al. 2010; Madhavarao et al. 2004). Tissue sections were incubated overnight with anti-ASPA antibodies at a dilution of 1:30,000, or anti-AceCS1 antibodies at a dilution of 1:5,000. Bound antibodies were visualized by the avidin-biotin complex method with horseradish peroxidase as the enzyme marker (Vectastain Elite; Vector Labs, Burlingame, CA), and were developed with a $\mathrm{Ni}$ and $\mathrm{Co}$ enhanced diaminobenzidene chromogen (Pierce Chemical, Rockford, IL). Images were adjusted for brightness and contrast using PC-based imaging software (Media Cybernetics, Silver Spring, MD, and Adobe Systems, San Jose, CA).

SDS-PAGE and western blotting

SDS-PAGE and western blotting of brain proteins was done as previously described (Hershfield et al. 2006). Adult wild-type and tremor rats were deeply anesthetized prior to sacrifice, and the brains were removed, frozen on dry ice, and stored at $-80^{\circ} \mathrm{C}$ until use. Tissue homogenates were prepared with a Potter-Elvejham homogenizer in isolation medium. Homogenates were centrifuged $(16,000 \mathrm{~g}, 10 \mathrm{~min}$, $4^{\circ} \mathrm{C}$ ) and the supernatants were used for SDS-PAGE. Protein concentrations were determined by Bio-Rad's DC protein assay (Hercules, CA), and $60 \mu \mathrm{g}$ of protein were loaded per sample. Following electrophoresis, samples were transferred to Immobilon-P PVDF membranes and incubated overnight with the ASPA peptide antibody (1:15,000 dilution) at $4^{\circ} \mathrm{C}$. Membranes were washed in PBS, and then incubated for $1 \mathrm{~h}$ with horseradish peroxidase-conjugated goat anti-rabbit secondary antibody at a dilution of 1:2,500. Membranes were washed and developed with diaminobenzidine substrate.

\section{GTA treatment of tremor rats}

GTA was given orally to tremor rat pups once in the morning (9:00-10:00 am) and once in the evening (4:30-5:30 pm) starting from day 7 after birth at a dose of $4.2 \mathrm{~g} / \mathrm{kg}$ until day 14. The dose of GTA was increased to $5.8 \mathrm{~g} / \mathrm{kg}$ on day 15 until the pups were weaned (22/23 days after birth). After weaning, the pups received GTA in their rat food (7.5\% of GTA by weight) and water (5\% GTA by weight). The untreated tremor rat pups were given normal rat feed and water after weaning up to approximately 4 months.

\section{Rotarod performance evaluation}

Each Rotarod treadmill (Med Associates, Georgia, VT) consisted of a motor-driven drum with constant speed or accelerating speed modes of operation. The drum allows each animal to maintain a suitable grip. The equipment consisted of a metal frame of rotating rods $(25.5 \mathrm{~cm}$ high from the bench, $6.0 \mathrm{~cm}$ diameter). The cylinders were connected to a variable speed reversible motor, allowing the speed and direction of rotation of the cylinders to be changed. Rats were tested using an accelerated Rotarod protocol with progressively increasing speed from 2 to $20 \mathrm{rpm}$. Motor performance was monitored for $3 \mathrm{~min}$ per trial. After the treated and untreated tremor rats reached 45 days of age, they were tested biweekly on the Rotarod treadmill over the course of GTA treatment (up to $\sim 4$ months). For each time point, 5 trials were conducted for each rat and the average balance time in seconds was recorded.

Locomotion evaluation

Locomotor activity was measured using an Acuscan animal activity monitor with infrared photocell system (model RXYZCM; Omnitech, Acuscan Electronics, Columbus, $\mathrm{OH})$, located in a dedicated room within the animal facility as previously described (Elliott et al. 2004). Briefly, animals were placed singly in a $40 \times 40 \times 30(\mathrm{~L} \times \mathrm{W} \times \mathrm{H})$ $\mathrm{cm}$ clear Plexiglas arena and lid with multiple $3.5-\mathrm{cm}-$ diameter holes placed on top of the arena. One hour of 
activity was monitored, and data were automatically gathered and transmitted to computer via an Omnitech Model DCM-I-BBU Digiscan analyzer.

Statistical analyses of the Rotarod data and locomotion data

These studies were conducted over a 2.5 -year period due to the difficulties in breeding adequate numbers of tremor mutant pups from heterozygote adults. As such, there were fewer rats per group at the outset of the study. The mutant rat pups from different litters were randomly assigned after birth to treated and untreated groups in the two categories of male and female tremor rats. This led to unequal and variable group sizes that precluded using repeated measures ANOVA to analyze the data. The average Rotarod balance time (s) data failed the assumption of normality or equal variance or both and therefore was analyzed by KruskalWallis ANOVA of the ranks. When the $H$ statistic was found to be significant the differences in ranks were compared by the method of Dunn. Rotarod performance was compared at different ages of the tremor rats (time points) as well as the averages of all the time points over the course of the study.

The data on locomotion parameters including horizontal activity units (number of events), total distance moved (cm) and move time (s) were also analyzed at different time points. One-way ANOVA was performed directly on the average values and the significant $F$ statistic was followed by a post-hoc test method (Holm-Sidak) for significance of mean differences. All statistical analyses were performed using either the SPSS package for statistical analyses version 14.0 or Sigma Plot version 11.0. The results were identical when an analysis was repeated by interchanging the software.

\section{Quantification of vacuolation}

Rats were euthanized at the end of the study ( $\sim 110$ days for wild-type rats and $\sim 120$ days for tremor rats). Animals were anesthetized and the brain tissue fixed by transcardial perfusion with buffered formalin. Formalin-fixed, paraffinembedded brain sections ( $\sim 7$ micrometer) were stained with hematoxylin and eosin for scoring of vacuolation. The cerebellum/brain stem and spinal cord showed changes in the vacuolation pattern in treated and untreated rats. A random set of processed slides were drawn for analyses, and they were scored for severity of vacuolation by a board-certified veterinary pathologist blinded to the study. The sections were scored 0 (no vacuolation), 1 (mild vacuolation), 2 (moderate vacuolation), and 3 (severe vacuolation), and the normalized score was computed and expressed as a percentage as [(sum of all the scores) $/($ total of possible maximum scores $)]^{*}(100)$.
Regression analysis of severity of vacuolation and Rotarod performance

The average Rotarod performance of the sampled rats was compared individually against the score they received for severity of vacuolation in the cerebellum/ brain stem and spinal cord and analyzed separately for the two regions. A regression analysis was performed (Sigma Plot version 11.0) to determine the degree of correlation between the vacuolation scoring pattern and Rotarod performance, and to determine if there was a treatment effect.

\section{Myelin preparation and TLC for myelin lipids}

Rat brain myelin was isolated as previously described (Madhavarao et al. 2005) using the procedure of Norton and Poduslo (1973). Briefly, rat brains were homogenized $(10 \% \mathrm{w} / \mathrm{v})$ using a polytron blender with isolation and resuspension buffer (50 mM Tris- $\mathrm{HCl}, 50 \mathrm{mM} \mathrm{NaCl}, 0.32 \mathrm{M}$ sucrose) and protease inhibitor cocktail according to the manufacturer's instructions (Sigma-Aldrich) and the myelin was isolated by sucrose density gradient and centrifugation (75,000 $\mathrm{g}$ for $25 \mathrm{~min}$ ). The myelin fraction was subjected to hypo-osmotic shock, centrifuged $(12,000 \mathrm{~g}$ for $10 \mathrm{~min})$ and collected as a pellet. The pellet was suspended in $0.5 \mathrm{ml}$ resuspension buffer ( $50 \mathrm{mM}$ Tris- $\mathrm{HCl}, 50 \mathrm{mM} \mathrm{NaCl}, 0.32 \mathrm{M}$ sucrose). Myelin was extracted using 2:1 chloroform: methanol and the myelin proteins were solubilized in $0.1 \mathrm{~N} \mathrm{NaOH}$ for 3 days and protein content quantified using a commercial kit (Bio-Rad).

Myelin lipids were separated by two-dimensional TLC as previously described (Madhavarao et al. 2005) with the following adjustments. First dimension: solvent system 1 (diethyl ether: benzene: ethanol: acetic acid; 40:50:2:0.2 $\mathrm{v} / \mathrm{v}$ ) solvent front advanced $2 / 3$ rds plate height and dried. Solvent system 2 (diethyl ether: hexane; 6:94 v/v) was run the full plate height. Second dimension: solvent system 1 (chloroform: methanol: ammonium hydroxide; 50:30:1 v/v) solvent front advanced to half the plate height and dried. Solvent system 2 (chloroform: methanol; 10:3 v/v) was run the full course of the second dimension. The spots were developed by spraying with bromophenol blue dye $(0.05 \%$ in $50 \%$ methanol solution $)$ with slight heating. Spot intensities were quantified from digital photographs using PC-based imaging software (Adobe Systems). Individual lipid spot intensities were expressed as a fraction of the total lipid intensity value obtained by summation of values for all discernible lipid spots in a single TLC run. The individual lipid spot values were then normalized to myelin protein concentrations as previously described (Madhavarao et al. 2005). 


\section{Results}

\section{Genotyping}

Tremor rat genotypes were confirmed by PCR. The heterozygotes $(\mathrm{tm} /+)$ and tremor rats $(\mathrm{tm} / \mathrm{tm})$ yielded a 179-bp PCR product which is absent in wild-type rats $(+/+)$. Molecular genotyping is necessary for the identification of the heterozygotes used to breed the mutant tremor rats.

\section{ASPA immunohistochemistry and western blotting}

ASPA immunohistochemistry was used to confirm the ASPA-null phenotype in tremor rats. Figure 1 shows brain sections from wild-type and tremor rats stained with an antibody against human ASPA (Hershfield et al. 2006). ASPA expression was strong in oligodendrocytes in wildtype rats (Fig. 1a), whereas expression was undetectable in tremor rats (Fig. 1b). Western blots showed an approxi-

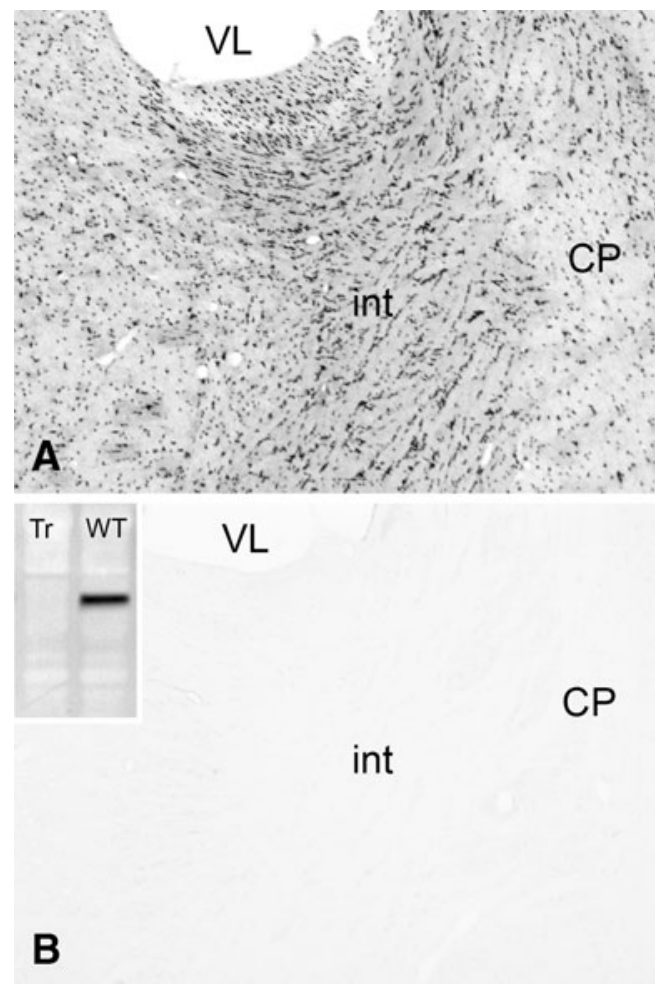

Fig. 1 Immunohistochemistry and western blots were used to confirm the ASPA null phenotype in tremor rats. ASPA expression is shown for wild-type (a), and tremor rats (b). ASPA-immunoreactive cells in (a) are predominantly oligodendrocytes in the internal capsule, and surrounding forebrain fiber tracts. Immunoreactivity is absent in brain tissue from tremor rats (b). Inset in (b) is a western blot of brain protein extracts from wild-type $(W T)$ and tremor rats (Tr) showing a single immunoreactive band at approximately $37 \mathrm{kD}$ in the wild-type rat extract that is absent in the tremor rat extract. $V L$ Lateral ventricle, int internal capsule, $C P$ caudate putamen mately $37-\mathrm{kD}$ protein band in brain extracts from normal Kyoto Wistar rats which was absent in brain extracts from tremor rats (inset in Fig. 1b). These results confirmed the ASPA-null genotype in tremor rats and demonstrated the total lack of protein expression in homozygous $(\mathrm{tm} / \mathrm{tm})$ rats.

Rotarod treadmill performance

An accelerated Rotarod treadmill test was used to evaluate coordination and motor performance in GTA-treated and untreated tremor rats. GTA treatment significantly improved tremor rat performance on the Rotarod treadmill over the entire course of the trials (Fig. 2). Treated tremor rats improved their performance over time, whereas untreated tremor rats did not. GTA-treated female tremor rats (Fig. 2a) showed a greater improvement in Rotarod performance than males (Fig. 2b). GTA treatment did not affect the performance of wild-type rats (data not given). Treated female tremor rat performance on the Rotarod reached approximately $50 \%$ of the values observed for wild-type rats (average balance time of $157 \pm 15$ seconds for wild-type rats, $76 \pm 11 \mathrm{~s}$ for GTA-treated female tremor rats, and $27 \pm 5 \mathrm{~s}$ for untreated female tremor rats). Treadmill

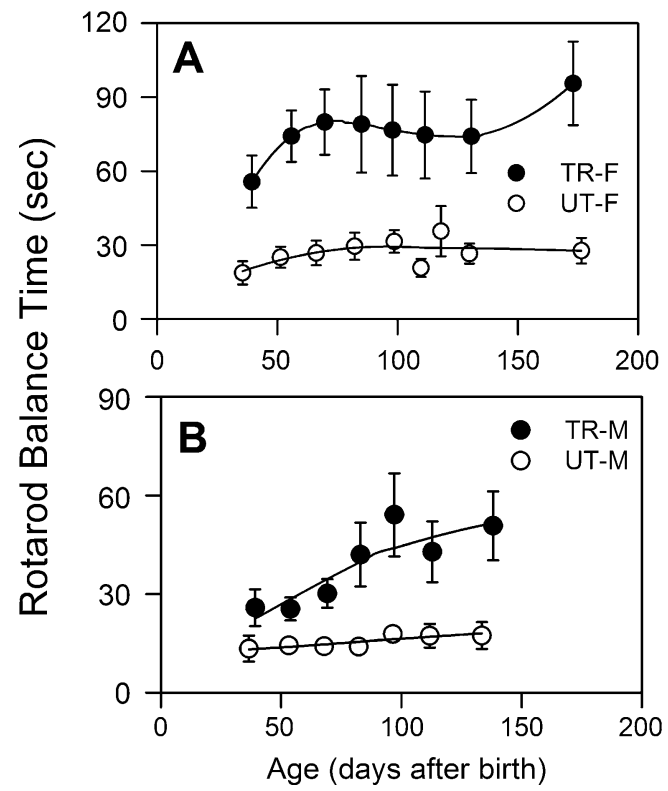

Fig. 2 Longitudinal study of Rotarod performance in GTA-treated and untreated tremor rats. The differences between the GTA-treated and untreated groups were significant by ANOVA $(p<0.001)$ and significant by post-hoc analysis with Tukey's HSD $(p<0.05)$. Rotarod performance of female tremor rats is shown in (a), performance of male tremor rats is shown in (b). Animal numbers per test session were variable; $n=11-16$ (av. 12) for treated tremor females (TR-F), 4 18 (av. 12) for untreated tremor females $(U T-F), 9-14$ (av. 10) for treated tremor males $(T R-M)$, and 7-16 (av. 11) for untreated tremor males $(U T-M)$. See Table 2 for statistical analyses of individual testing sessions 
balancing times for treated tremor females were approximately three times greater than untreated females, and for males, the values were approximately doubled. See Table 1 for statistical analysis of the Rotarod data.

\section{Locomotion analysis}

ASPA deficiency severely impairs motor function and reduces spontaneous ambulatory and exploratory activity. To assess the effects of GTA treatment on locomotion and exploratory activity, we analyzed animal movements, including horizontal movements, distance moved, and move time using an Acuscan automated activity chamber. Animals were tested multiple times starting at around 40 days of age, but statistically significant differences in locomotion were not observed until animals were approximately 70 days old. Statistically significant differences were observed during the last 4 testing sessions at 70,85 , 98 , and 110 days of age. GTA treatment significantly increased activity levels in male and female tremor rats, with greater improvements tending to occur later in the study. Figure 3 shows the comparison of average values of open-field parameters for the treated and untreated tremor rats at 98 and 110 days of age. Treated female tremor rats exhibited the most significant differences in locomotion from untreated females at 98 days, whereas treated male tremor rats showed the most significant improvements at
110 days. See Table 2 for statistical analysis of the locomotion data.

Vacuolation scoring and regression analysis with Rotarod data

Severe vacuolation of thalamus, hypothalamus, brain stem, and spinal cord is a characteristic feature of Canavan disease pathology (Adachi et al. 1973). It is also observed in the animal models of the disease, including tremor rats. To determine if GTA treatment had positive effects in reducing brain vacuolation, a veterinary pathologist who was blinded to the treatment groups scored the vacuolation in cerebellum/ brain stem and spinal cord from a randomly selected group of the animals used for the Rotarod and locomotion analyses. Figure 4 shows regression analyses between the vacuolation scoring and performance on the Rotarod balance test. The regression plot for the vacuolation in cerebellum/brain stem versus Rotarod data is given in Fig. 4a, whereas the plot for vacuolation in the spinal cord versus Rotarod data is given in Fig. $4 \mathrm{~b}$. The decreased vacuolation in cerebellum/brain stem and spinal cord was positively correlated with the motor improvements observed using the Rotarod treadmill. The correlation coefficients $(r)$ determined for plots (a) and (b) were 0.72 and 0.61 , and were found to be significant with $p$ values of 0.01 and 0.04 for the $F$ values of 13.15 and 7.79 (by ANOVA), respectively.

Table 1 Statistical analysis of Rotarod balance time (s) at different ages and the average performance over the entire study of the GTA-treated and untreated female and male tremor rats

\begin{tabular}{|c|c|c|c|c|}
\hline Average age of the groups & ANOVA statistic & Groups compared & Significance ( $p$ value) & Test method \\
\hline 37 days & $\begin{array}{l}\text { Unadjusted } \\
H=14.94(\mathrm{p}=0.002)\end{array}$ & $\begin{array}{l}\text { TR-F vs UT-F } \\
\text { TR-M vs UT-M }\end{array}$ & $\begin{array}{l}\text { NS } \\
\text { NS }\end{array}$ & Dunn \\
\hline 53 days & $\begin{array}{l}\text { Unadjusted } \\
H=23.17(p<0.001)\end{array}$ & $\begin{array}{l}\text { TR-F vs UT-F } \\
\text { TR-M vs UT-M }\end{array}$ & $\begin{array}{l}p<0.05 \\
\mathrm{NS}\end{array}$ & Dunn \\
\hline 68 days & $\begin{array}{l}\text { Unadjusted } \\
H=24.93(p<0.001)\end{array}$ & $\begin{array}{l}\text { TR-F vs UT-F } \\
\text { TR-M vs UT-M }\end{array}$ & $\begin{array}{l}p<0.05 \\
\text { NS }\end{array}$ & Dunn \\
\hline 83 days & $\begin{array}{l}\text { Unadjusted } \\
H=17.74(p<0.001)\end{array}$ & $\begin{array}{l}\text { TR-F vs UT-F } \\
\text { TR-M vs UT-M }\end{array}$ & $\begin{array}{l}\mathrm{NS} \\
p<0.05\end{array}$ & Dunn \\
\hline 97 days & $\begin{array}{l}\text { Unadjusted } \\
H=15.74(p=0.001)\end{array}$ & $\begin{array}{l}\text { TR-F vs UT-F } \\
\text { TR-M vs UT-M }\end{array}$ & $\begin{array}{l}\mathrm{NS} \\
p<0.05\end{array}$ & Dunn \\
\hline 111 days & $\begin{array}{l}\text { Unadjusted } \\
H=16.60(p<0.001)\end{array}$ & $\begin{array}{l}\text { TR-F vs UT-F } \\
\text { TR-M vs UT-M }\end{array}$ & $\begin{array}{l}p<0.05 \\
p<0.05\end{array}$ & Dunn \\
\hline 133 days & $\begin{array}{l}\text { Unadjusted } \\
H=14.34(p=0.002)\end{array}$ & $\begin{array}{l}\text { TR-F vs UT-F } \\
\text { TR-M vs UT-M }\end{array}$ & $\begin{array}{l}\text { NS } \\
p<0.05\end{array}$ & Dunn \\
\hline Over the course of study & $\begin{array}{l}\text { Unadjusted } \\
H=25.98(p<0.001)\end{array}$ & $\begin{array}{l}\text { TR-F vs UT-F } \\
\text { TR-M vs UT-M }\end{array}$ & $\begin{array}{l}p<0.05 \\
p<0.05\end{array}$ & Dunn \\
\hline
\end{tabular}

Average Rotarod balance times of treated female $(T R-F)$, untreated female $(U T-F)$, treated male $(T R-M)$, and untreated male $(U T-M)$ tremor rats were included for analysis. One-way ANOVA on the ranks of the average Rotarod balance times was performed by Kruskal-Wallis method since the data failed either the test of normality or the test of equal variance or both. The $H$ statistic was verified for significance. The differences between the median values were tested to rule out chance by Dunn's method. $p$ values greater than 0.1 are indicated as NS (not significant) 
Fig. 3 Average values of total horizontal activity, distance moved $(\mathrm{cm})$ and move time $(\mathrm{s})$ were recorded for the treated and untreated tremor rats at 4 time points at approximately 70 , 85,98 , and $110( \pm 3)$ days of age. The data were collected for $1 \mathrm{~h}$ in an open-field apparatus. Data are shown for testing at 98 and 110 days of age; the testing days when treated female and treated male tremor rats showed the greatest improvements respectively. The number of rats in the different groups tested were as follows: treated female ( $\mathrm{Tr}$ Fem, 12); untreated female (Ut Fem, 15); treated male (Tr Male, $12)$, and untreated male (Ut Male, 14)
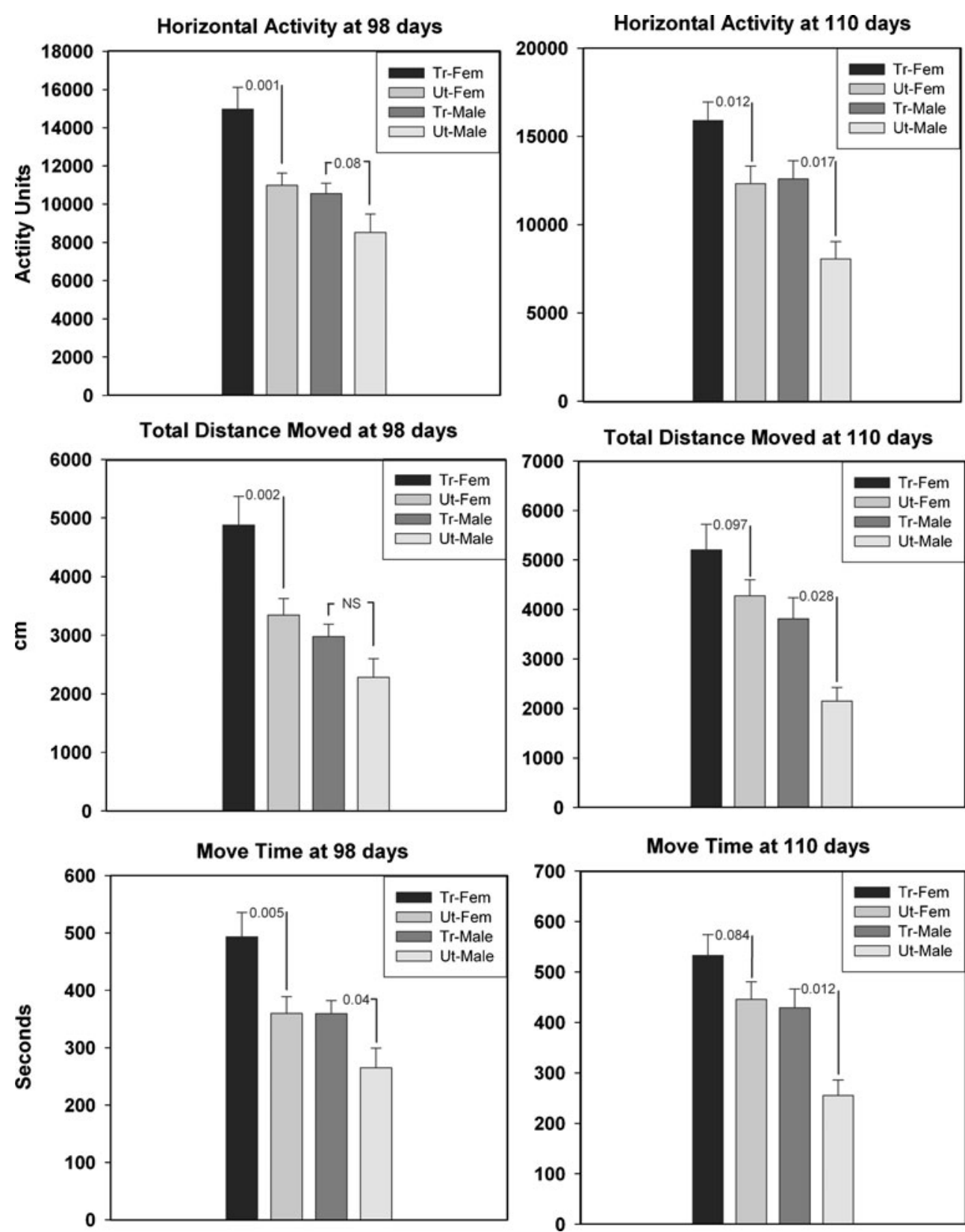

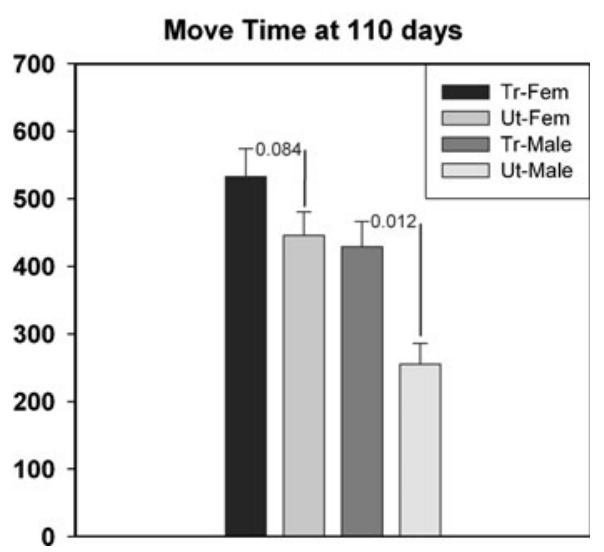

Lipid analysis

Myelin lipid content in treated and untreated tremor rats was analyzed by 2-dimensional thin layer chromatography (2D TLC). Table 3 presents the intensity values for the lipid spots on the 2D TLC plates for the treated and untreated female tremor rats. Changes in lipid content in the treated male tremor rats did not reach statistical significance (data not shown). Galactocerebroside levels in the female GTAtreated tremor rats were increased by approximately $20 \%$, which did reach significance ( $p \leq 0.05, n=4-5)$. Galactocerebrosides are one of the critical myelin-associated lipids that have been found to be specifically reduced in Canavan disease (Madhavarao et al. 2005; Wang et al. 2009). Improvements were observed in a number of other myelin lipids including sphingomyelin, phosphatidylethanolamine, phosphatidylglycerol, sulfatides, ceramides containing $\alpha$ hydroxy fatty acids, and cholesterol, but due to inter-animal variability, these changes were not large enough to reach statistical significance.

AceCS1 immunoreactivity in 18-day-old and adult wild-type rats and adult tremor rats

Free acetate derived from the hydrolysis of GTA in the brain, as well the free acetate derived by the ASPA- 
Table 2 Statistical analyses of locomotion parameters measured on an open field apparatus for the treated and untreated tremor rats

\begin{tabular}{|c|c|c|c|c|c|}
\hline Parameter & $\begin{array}{l}\text { Average age of } \\
\text { groups }^{\text {a }}\end{array}$ & $\begin{array}{l}\text { Groups } \\
\text { compared }\end{array}$ & ANOVA statistic ${ }^{\mathrm{b}}$ & $\begin{array}{l}\text { Significance of difference between } \\
\text { groups }(p \text { value })^{c}\end{array}$ & $\begin{array}{l}\text { Test } \\
\text { method }\end{array}$ \\
\hline \multirow[t]{8}{*}{$\begin{array}{l}\text { Total horizontal activity } \\
\text { (movements) }\end{array}$} & \multirow[t]{2}{*}{70 days } & $\begin{array}{l}\text { TR-F vs } \\
\text { UT-F }\end{array}$ & $F=7.21(p \leq 0.001)$ & NS & \multirow[t]{2}{*}{$\begin{array}{l}\text { Holm- } \\
\text { Sidak }\end{array}$} \\
\hline & & $\begin{array}{l}\text { TR-M vs } \\
\text { UT-M }\end{array}$ & & 0.04 (unadjusted) & \\
\hline & \multirow[t]{2}{*}{85 days } & $\begin{array}{l}\text { TR-F vs } \\
\text { UT-F }\end{array}$ & $F=4.98(p=0.004)$ & 0.025 (unadjusted) & \multirow[t]{2}{*}{$\begin{array}{l}\text { Holm- } \\
\text { Sidak }\end{array}$} \\
\hline & & $\begin{array}{l}\text { TR-M vs } \\
\text { UT-M }\end{array}$ & & 0.053 (unadjusted) & \\
\hline & \multirow[t]{2}{*}{98 days } & $\begin{array}{l}\text { TR-F vs } \\
\text { UT-F }\end{array}$ & $F=10.04(p \leq 0.001)$ & 0.001 (unadjusted) & \multirow[t]{2}{*}{$\begin{array}{l}\text { Holm- } \\
\text { Sidak }\end{array}$} \\
\hline & & $\begin{array}{l}\text { TR-M vs } \\
\text { UT-M }\end{array}$ & & 0.08 (unadjusted) & \\
\hline & \multirow[t]{2}{*}{110 days } & $\begin{array}{l}\text { TR-F vs } \\
\text { UT-F }\end{array}$ & $F=7.19(p \leq 0.001)$ & 0.012 (unadjusted) & \multirow[t]{2}{*}{$\begin{array}{l}\text { Holm- } \\
\text { Sidak }\end{array}$} \\
\hline & & $\begin{array}{l}\text { TR-M vs } \\
\text { UT-M }\end{array}$ & & 0.017 (unadjusted) & \\
\hline \multirow[t]{8}{*}{ Total distance moved $(\mathrm{cm})$} & \multirow[t]{2}{*}{70 days } & $\begin{array}{l}\text { TR-F vs } \\
\text { UT-F }\end{array}$ & $\begin{array}{l}\text { Unadjusted } H=23.5 \\
\quad(p \leq 0.001)\end{array}$ & NS & \multirow[t]{2}{*}{ Dunn } \\
\hline & & $\begin{array}{l}\text { TR-M vs } \\
\text { UT-M }\end{array}$ & & NS & \\
\hline & \multirow[t]{2}{*}{85 days } & $\begin{array}{l}\text { TR-F vs } \\
\text { UT-F }\end{array}$ & $\begin{array}{l}\text { Unadjusted } H=11.3 \\
\quad(p \leq 0.01)\end{array}$ & NS & \multirow[t]{2}{*}{ Dunn } \\
\hline & & $\begin{array}{l}\text { TR-M vs } \\
\text { UT-M }\end{array}$ & & NS & \\
\hline & \multirow[t]{2}{*}{98 days } & $\begin{array}{l}\text { TR-F vs } \\
\text { UT-F }\end{array}$ & $F=10.26(p \leq 0.001)$ & 0.002 (unadjusted) & \multirow[t]{2}{*}{$\begin{array}{l}\text { Holm- } \\
\text { Sidak }\end{array}$} \\
\hline & & $\begin{array}{l}\text { TR-M vs } \\
\text { UT-M }\end{array}$ & & NS & \\
\hline & \multirow[t]{2}{*}{110 days } & $\begin{array}{l}\text { TR-F vs } \\
\text { UT-F }\end{array}$ & $F=6.7(p=0.001)$ & 0.097 (unadjusted) & \multirow[t]{2}{*}{$\begin{array}{l}\text { Holm- } \\
\text { Sidak }\end{array}$} \\
\hline & & $\begin{array}{l}\text { TR-M vs } \\
\text { UT-M }\end{array}$ & & 0.028 (unadjusted) & \\
\hline \multirow[t]{8}{*}{ Total move time (sec) } & \multirow[t]{2}{*}{70 days } & $\begin{array}{l}\text { TR-F vs } \\
\text { UT-F }\end{array}$ & $F=10.69(p \leq 0.001)$ & NS & \multirow[t]{2}{*}{$\begin{array}{l}\text { Holm- } \\
\text { Sidak }\end{array}$} \\
\hline & & $\begin{array}{l}\text { TR-M vs } \\
\text { UT-M }\end{array}$ & & 0.01 (unadjusted) & \\
\hline & \multirow[t]{2}{*}{85 days } & $\begin{array}{l}\text { TR-F vs } \\
\text { UT-F }\end{array}$ & $F=5.6(p=0.002)$ & 0.01 (unadjusted) & \multirow[t]{2}{*}{$\begin{array}{l}\text { Holm- } \\
\text { Sidak }\end{array}$} \\
\hline & & $\begin{array}{l}\text { TR-M vs } \\
\text { UT-M }\end{array}$ & & 0.06 (unadjusted) & \\
\hline & \multirow[t]{2}{*}{98 days } & $\begin{array}{l}\text { TR-F vs } \\
\text { UT-F }\end{array}$ & $F=7.7(p \leq 0.001)$ & 0.005 (unadjusted) & \multirow[t]{2}{*}{$\begin{array}{l}\text { Holm- } \\
\text { Sidak }\end{array}$} \\
\hline & & $\begin{array}{l}\text { TR-M vs } \\
\text { UT-M }\end{array}$ & & 0.04 (unadjusted) & \\
\hline & \multirow[t]{2}{*}{110 days } & $\begin{array}{l}\text { TR-F vs } \\
\text { UT-F }\end{array}$ & $F=6.63(p=0.001)$ & 0.084 (unadjusted) & \multirow[t]{2}{*}{$\begin{array}{l}\text { Holm- } \\
\text { Sidak }\end{array}$} \\
\hline & & $\begin{array}{l}\text { TR-M vs } \\
\text { UT-M }\end{array}$ & & 0.012 (unadjusted) & \\
\hline
\end{tabular}

Statistics are given for the locomotion data including total horizontal activity movements, total distance moved, and total move time over the course of a 1-h observation period on 4 different testing sessions ( $70,85,98$, and 110 days of age)

${ }^{\text {a }}$ Data were collected starting from $\sim 40$-day-old tremor rats but statistically discernible differences between the treated and untreated groups were not found until the tremor rats reached around 70 days of age

${ }^{\mathrm{b}}$ One-way ANOVA was performed on the mean values of treated female $(T R-F)$, untreated female $(U T-F)$, treated male $(T R-M)$ and untreated male $(U T-M)$ tremor rats and the $F$ statistic was verified for significance when the data conformed to assumptions of normality and equal variance. When the data did not conform to the either or both of the assumptions, one-way ANOVA on the ranks was performed by Kruskal-Wallis method and the $H$ statistic was verified for significance

${ }^{\mathrm{c}} p$ values greater than 0.1 are indicated as $N S$ (not significant) 


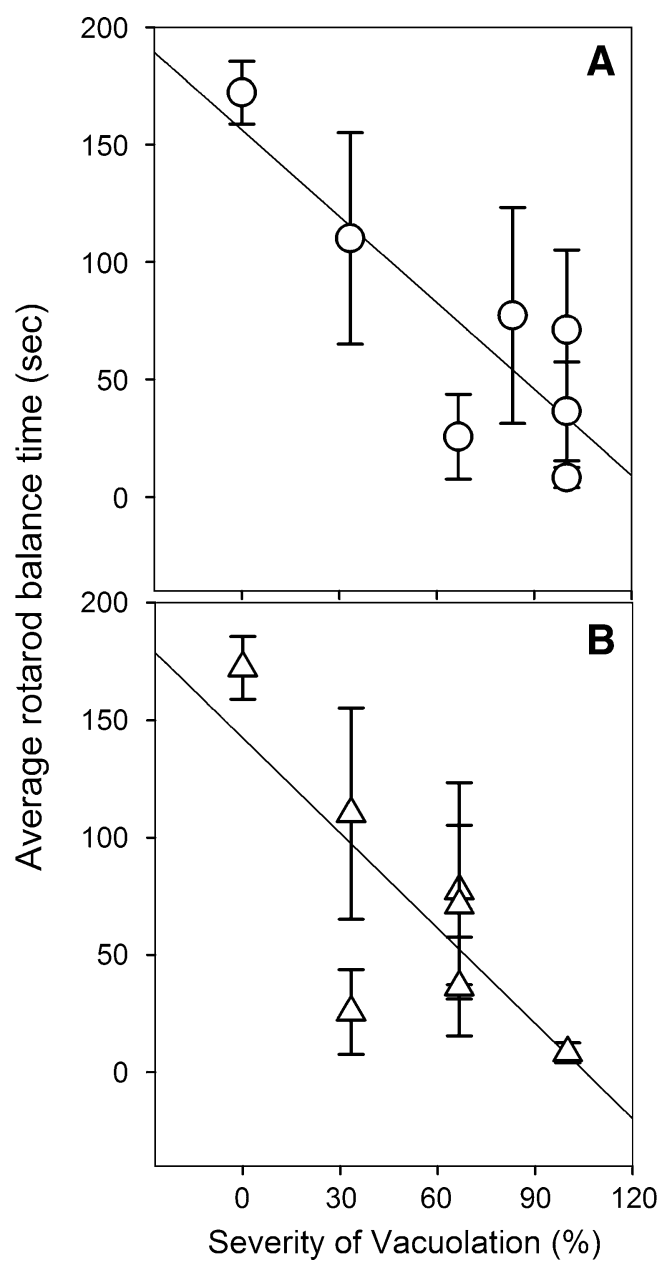

Fig. 4 Regression analysis of the severity of vacuolation in the cerebellum/brain stem (a) and spinal cord (b) with the average Rotarod performance of individual rats $(n=7)$. The randomly selected sample consisted of 2 untreated female tremor rats, 2 treated female tremor rats, one untreated male tremor rat, one treated male tremor rat, and one untreated female wild-type rat of the same strain. The correlation coefficients, $r$, determined for plots (a) and (b) were 0.72 and 0.61 , and were found to be significant with $p$ values of 0.01 and 0.04 for the $F$ values of 13.15 and 7.79 (by ANOVA), respectively. The vacuolation scores were determined by a veterinary pathologist blinded to the study. The values for the treated tremor rats tended to fall intermediate between values found for the untreated tremor rats and the wild-type rat

mediated hydrolysis of NAA, must be converted to acetyl coenzyme A before it can be further metabolized. We hypothesized that the most likely candidate enzyme for this metabolic reaction is acetyl coenzyme A synthase-1 (AceCS1) (Moffett et al. 2007), which converts free acetate and coenzyme A to acetyl coenzyme A for lipid synthesis, among other functions. In order to begin addressing this question, we employed antibodies to AceCS1 (Ariyannur et al. 2010) to determine if oligodendrocytes express this enzyme during the peak period of postnatal myelination (18 days of age in rats). We found that AceCS1 is expressed predominantly in cell nuclei throughout the brain (Fig. 5).
Table 3 Average values of myelin lipids (spot intensities) in female rats

\begin{tabular}{|c|c|c|c|c|c|c|}
\hline & \multicolumn{2}{|c|}{ Wild-type } & \multicolumn{2}{|c|}{ Treated } & \multicolumn{2}{|c|}{ Untreated } \\
\hline & Mean & SEM & Mean & SEM & Mean & SEM \\
\hline PA & \multicolumn{2}{|c|}{$18,534 \pm 4,501$} & \multicolumn{2}{|c|}{$11,736 \pm 1,390$} & \multicolumn{2}{|c|}{$13,258 \pm 2,078$} \\
\hline $\mathrm{PC}$ & \multicolumn{2}{|c|}{$26,196 \pm 8,001$} & \multicolumn{2}{|c|}{$35,743 \pm 3,419$} & \multicolumn{2}{|c|}{$27,925 \pm 3,965$} \\
\hline SM & \multicolumn{2}{|c|}{$32,245 \pm 9,809$} & \multicolumn{2}{|c|}{$25,842 \pm 3,557$} & \multicolumn{2}{|c|}{$18,627 \pm 3,703$} \\
\hline PI & \multicolumn{2}{|c|}{$47,320 \pm 7,484$} & \multicolumn{2}{|c|}{$27,724 \pm 2,914$} & \multicolumn{2}{|c|}{$23,511 \pm 2,128$} \\
\hline PE & \multicolumn{2}{|c|}{$46,863 \pm 13,763$} & \multicolumn{2}{|c|}{$59,662 \pm 14,832$} & \multicolumn{2}{|c|}{$36,906 \pm 12,843$} \\
\hline PG & \multicolumn{2}{|c|}{$48,378 \pm 16,358$} & \multicolumn{2}{|c|}{$42,316 \pm 8,548$} & \multicolumn{2}{|c|}{$35,176 \pm 7,153$} \\
\hline Sulfatides & \multicolumn{2}{|c|}{$37,840 \pm 7,480$} & \multicolumn{2}{|c|}{$28,825 \pm 4,908$} & \multicolumn{2}{|c|}{$25,761 \pm 5,142$} \\
\hline $\mathrm{GC}^{*}$ & \multicolumn{2}{|c|}{$26,373 \pm 6,260$} & \multicolumn{2}{|c|}{$18,157 \pm 3,000$} & \multicolumn{2}{|c|}{$15,093 \pm 2,943$} \\
\hline HFAC & \multicolumn{2}{|c|}{$12,753 \pm 2,272$} & \multicolumn{2}{|c|}{$9,268 \pm 1,629$} & \multicolumn{2}{|c|}{$7,278 \pm 1,640$} \\
\hline Cholesterol & \multicolumn{2}{|c|}{$51,278 \pm 4,719$} & \multicolumn{2}{|c|}{$29,553 \pm 5,625$} & \multicolumn{2}{|c|}{$25,218 \pm 4,226$} \\
\hline
\end{tabular}

Mean values of myelin lipid levels ( $n=4-5$ for each value) from wildtype female rats and GTA-treated and untreated female tremor rats were compared by paired $t$ test. Many lipid values were increased with GTA treatment, but did not reach the $p<0.05$ significance level due to animal to animal variability. Galactocerebroside $\left(G C^{*}\right)$ levels were significantly different between the treated and untreated female tremor rats $(p<0.05)$. $P A$ Phosphatidic acid, $P C$ phosphatidylcholine, $S M$ sphingomyelin, $P I$ phosphatidylinositol, $P E$ phosphatidylethanolamine, $P G$ phosphatidylglycerol, sulfatides, HFAC ceramides containing $\alpha$-hydroxy fatty acids

Expression was strong in the nucleus and light to moderate in the cytoplasm of many oligodendrocytes in 18-day-old wild-type rats. Whereas the cytoplasmic localization of AceCS1 in oligodendrocytes is consistent with a role in myelin lipid synthesis, the prominent nuclear localization of AceCS1 in oligodendrocytes and other cell types in the brain may have implications for gene regulation and cellular differentiation and maturation (Copray et al. 2009; Kumar et al. 2009).

AceCS1 expression was upregulated in adult tremor rats as compared with controls (Figs. 6 and 7). AceCS1 was expressed moderately to strongly in some cellular nuclei in adult control rats, including neuronal and glial cell nuclei (Figs. 6a, b and 7a). In tremor rats, AceCS1 expression was substantially increased relative to control animals (Figs. 6c, $\mathrm{d}$ and 7b). GTA-treatment of tremor rats reduced AceCS1 expression relative to untreated tremor rats and returned expression levels closer to those observed in control rats (Figs. 6e, $\mathrm{f}$ and $7 \mathrm{c}$ ). In brain areas where severe vacuolation was observed in tremor rats, GTA treatment modestly reduced the degree of vacuolation. The lateral hypothalamus is one forebrain area that exhibits substantial vacuolation in tremor rats (Fig. 8). In wild-type control rats, AceCS1 expression was present in scattered cell nuclei throughout this region (Fig. 8a). In untreated tremor rats, AceCS1 expression was upregulated, and extensive vacuolation was observed in the lateral hypothalamus (Fig. 8b). 
Fig. 5 AceCS1-immunoreactivity in oligodendrocytes in white matter from an 18-day-old wild-type rat. The fimbria of the hippocampus is shown in (a) and (b), demonstrating numerous immunoreactive oligodendrocytes. AceCS1 expression in the corpus callosum of an 18-day-old rat is shown in (c) and (d). Immunoreactive oligodendrocytes in the internal capsule are shown in (e) and (f). AceCS1 expression was generally stronger in oligodendrocyte nuclei than in their cytoplasm. CA3 Pyramidal cell layer of hippocampal Ammon's horn $\mathrm{CA} 3$ region, $c c$ corpus callosum, $C P$ caudate/putamen, fim fimbria of the hippocampus, $i c$ internal capsule, $L V$ lateral ventricle, st stria terminalis. $B a r$ (in f): $120 \mu \mathrm{m}(\mathbf{a}, \mathbf{c}, \mathbf{e})$, $30 \mu \mathrm{m}(\mathbf{b}, \mathbf{d}, \mathbf{f})$

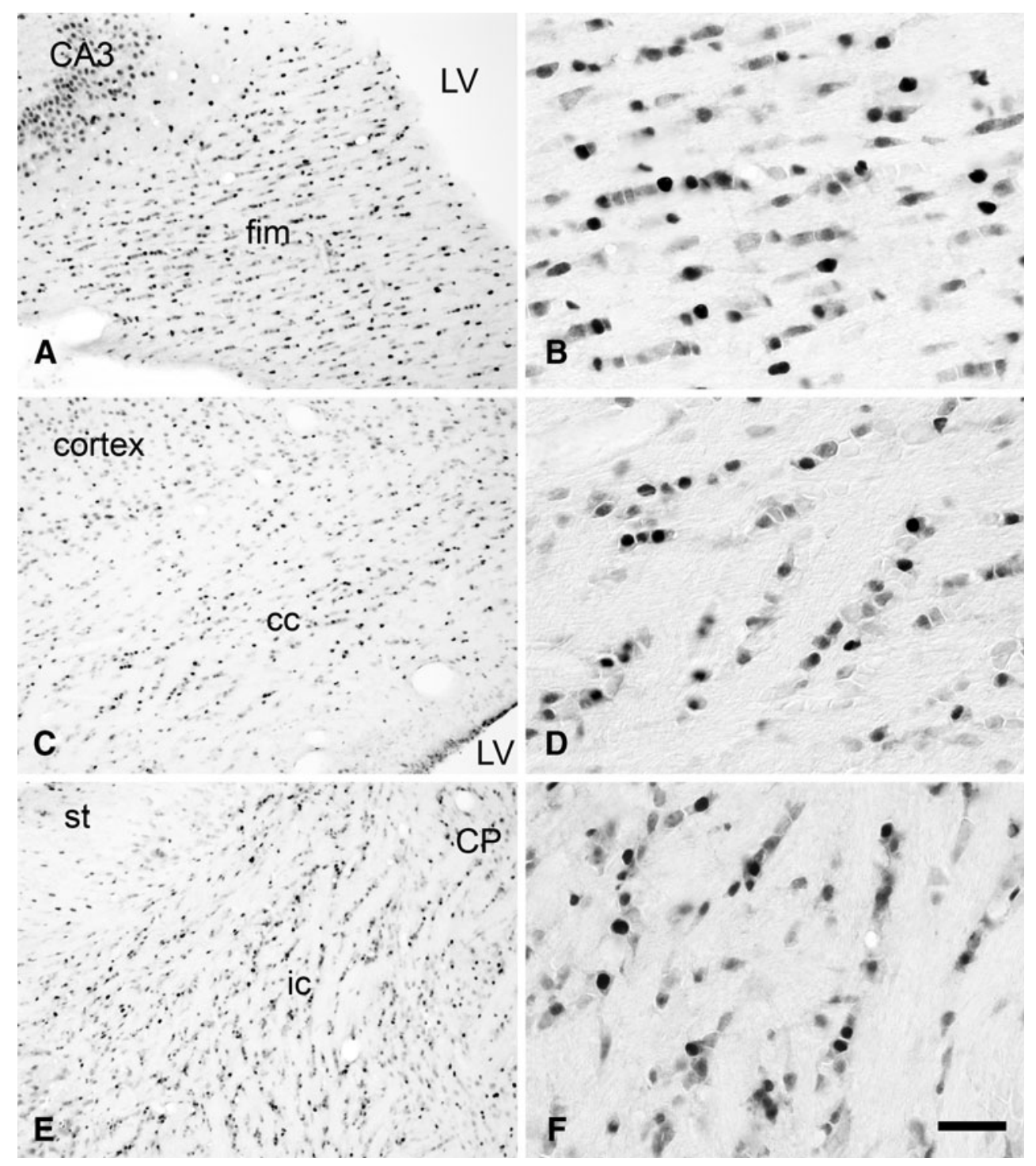

In GTA-treated tremor rats, AceCS1 expression was reduced to near control levels, and the degree of vacuolation was modestly reduced (Fig. 8c).

\section{Discussion}

Once the genetic basis of Canavan disease was discovered (Matalon et al. 1988), the primary question centered on whether the etiology involved toxic buildup of NAA, or impaired brain metabolism associated with the inability to catabolize NAA. Under the assumption that excess NAA was toxic, ASPA gene transfer appeared to be the most logical method of reversing the effects of ASPA deficiency in Canavan patients. This method has been attempted in animal models of Canavan disease (Klugmann et al. 2005; McPhee et al. 2005) and in a group of over 20 children with the disease (Janson et al. 2002; Leone et al. 2000). No positive long-term outcomes on motor function have been reported using ASPA gene transfer to ameliorate ASPA deficiency. Taking the approach that failure to metabolize NAA leads to a brain acetate deficiency during postnatal development and myelination, the current investigation is the first in a series of ongoing studies into the potential use of GTA supplementation for the treatment of Canavan disease.

We found that GTA is effective in significantly reducing the severe phenotypic sequelae of ASPA enzymatic deficiency in the tremor rat model of Canavan disease over the course of a 4-month study. In tremor rats treated with GTA, motor performance was significantly improved, with the greatest improvements occurring later in the longitudinal study (Fig. 2). Further, galactocerebroside content in myelin was modestly ( 20\%) but significantly increased (see Table 3). Galactocerebrosides are one of the functionally important classes of myelin-associated lipids that are 
Fig. 6 AceCS1-immunoreactivity comparison between adult wild, type and GTA treated and untreated tremor rats: low magnification images (left column), higher magnification images (right column). AceCS1 immunoreactivity in the cortex of an adult control rat $(\mathbf{a}, \mathbf{b})$ shows expression predominantly in cell nuclei in all layers of cortex. In a representative untreated adult tremor rat $(\mathbf{c}, \mathbf{d})$, AceCS1 expression was moderately upregulated, including in oligodendrocytes in the corpus callosum $(c c)$. In a representative adult GTA-treated tremor rat (e,f), AceCS1 expression was reduced relative to untreated tremor rats, and was similar to the expression levels in control animals. Bar (in f): $300 \mu \mathrm{m}(\mathbf{a}, \mathbf{c}, \mathbf{e}), 120 \mu \mathrm{m}(\mathbf{b}, \mathbf{d}, \mathbf{f})$

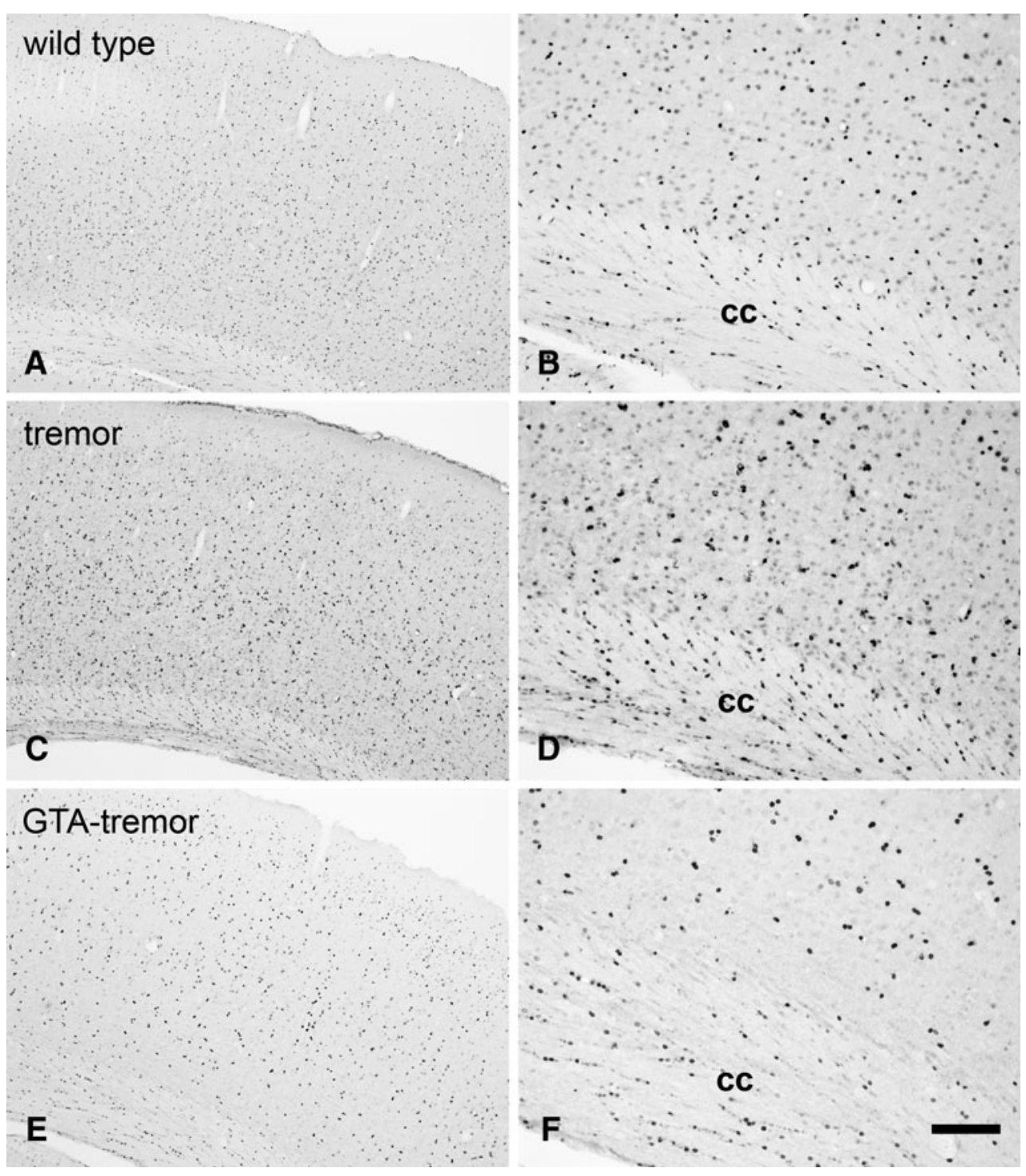

significantly reduced in Canavan disease patients and ASPA-deficient animal models (Madhavarao et al. 2005; Wang et al. 2009). Additionally, vacuolation in the brain and spinal cord was found to be modestly reduced with GTA treatment (Fig. 8), and the decreased vacuolation was positively correlated with improved performance on the Rotarod treadmill test (Fig. 4). These results support the acetate deficiency hypothesis of Canavan disease. Ongoing studies with ASPA -/- knockout mice (Matalon et al. 2000) are underway to confirm these results in another model system.

In previous studies, we found that administration of GTA to mice at a dose of $5.8 \mathrm{~g} / \mathrm{kg}$ increases acetate levels in the brain over 15-fold within an hour, and the levels remain elevated for several hours after administration (Mathew et al. 2005). Further, short and long term toxicity studies have shown that GTA is well tolerated (Bailey et al. 1991, 1992; Madhavarao et al. 2009). GTA does not require specific transport mechanisms to enter the cytoplasm of cells. Once internalized in cells, GTA is broken down to acetate and glycerol by the action of non-specific esterases. These factors make GTA especially useful for acetate delivery to the brain. Plasma acetate derived from GTA breakdown in the intestine, liver and bloodstream can also be taken up by the brain.

The current GTA treatment partially reversed the severe motor dysfunction of tremor rats. Rotarod treadmill motor performance scores in treated female tremor rats reached approximately $50 \%$ of those achieved by age-matched wild-type rats. This compares favorably with performance scores for untreated female tremor rats, which were only about $15 \%$ of those seen with wild-type rats. So, despite significant improvement in motor performance, the treated rats still had substantial leeway for further improvement. Additionally, GTA treatment improved the spongiform vacuolation in brain only partially, and substantial vacuo- 


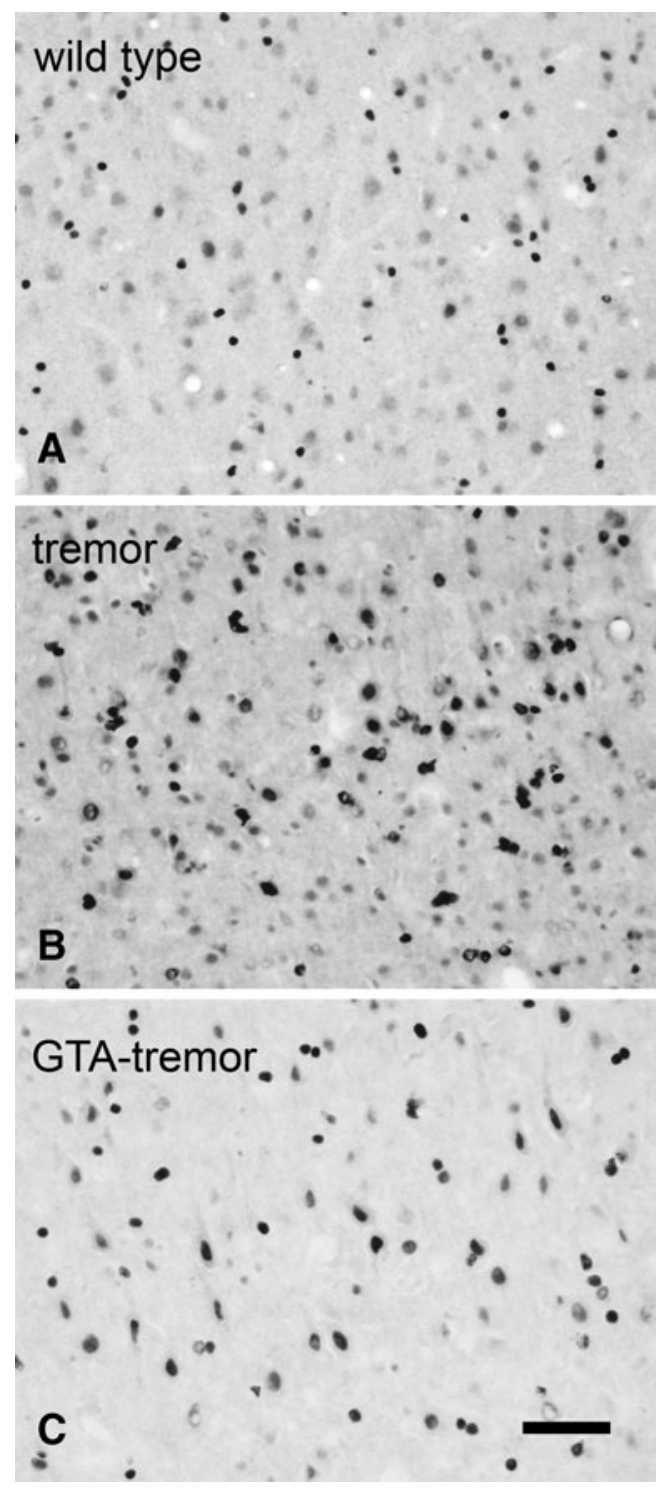

Fig. 7 AceCS1 expression in layer $\mathrm{V}$ of cortex. In wild-type adult rats, AceCS1 was expressed predominantly in scattered cell nuclei in layer $\mathrm{V}$ of cortex (a). In adult tremor rats, the number of immunoreactive cell nuclei in layer $\mathrm{V}$ was increased, and tended to occur in clusters not seen in wild-type rats (b). In GTA-treated tremor rats, the number of AceCS1 immunoreactive cell nuclei was reduced relative to untreated tremor rats, and tended to be more scattered as in the case of wild-type rats (c). Bar $60 \mu \mathrm{m}$

lation was still observed in GTA-treated tremor rats. Finally, myelin lipid content was improved modestly but did not reach wild-type levels, indicating that further optimization of the treatment regimen is necessary to increase effectiveness. Male and female tremor rats performed differently in treadmill balance time and locomotion testing. Female tremor rats consistently performed better than males. Additionally, female tremor rats responded more favorably to GTA treatment. The reason for the poor performance of the males is uncertain, but may relate to the
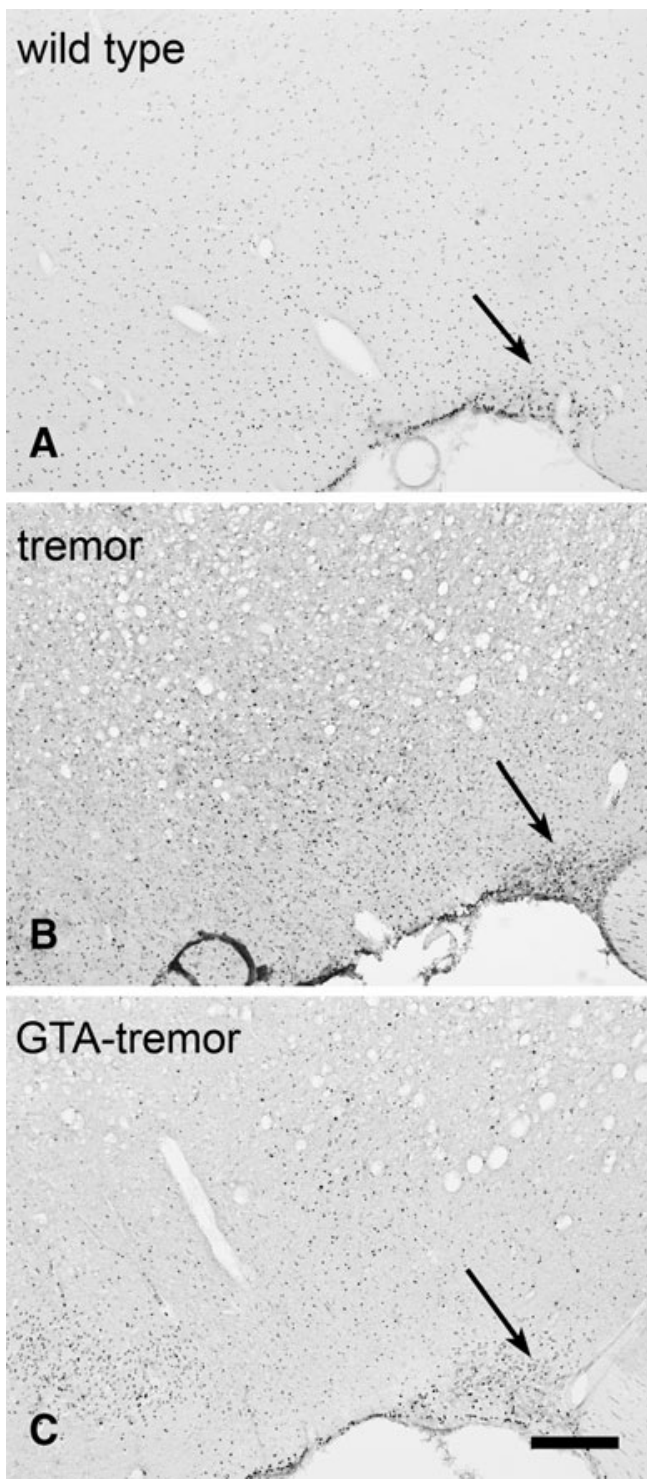

Fig. 8 AceCS1 expression and vacuole reduction in the lateral hypothalamus with GTA treatment. AceCS1-immunoreactivity in an adult wild-type rat (control) is shown in (a), with the supraoptic nucleus denoted by the arrow. The lateral hypothalamus of an adult tremor rat is shown in (b), exhibiting extensive vacuolation throughout the area, and upregulation of AceCS1 expression. The lateral hypothalamus of a GTA-treated adult tremor rat is shown in (c), with reduced AceCS1 expression and reduced vacuolation as compared with the untreated tremor rat. Bar $300 \mu \mathrm{m}$

genetic deletion in tremor rats, which spans three genes in addition to the gene for ASPA (Kitada et al. 2000).

Several possible improvements could be made to the current GTA supplementation regimen that may provide increased efficacy. GTA was only administered twice daily during the treatment period, and it may be found that increasing the frequency of administration provides greater recovery of function. In addition, GTA was administered in water, whereas it is likely that administration in a complete infant formula would provide increased efficacy due to 
improved nutrition. Further, tremor rat pups were not treated for the first postnatal week due to the difficulty in administering GTA orally to such young rats. It may be possible to increase acetate delivery to prenatal tremor pups and newborns by administering high levels of GTA to the pregnant and nursing maternal rats. Because esterase activity is high in gut and liver, it may be possible to increase acetate delivery to the brain by combining GTA with mild esterase inhibitors, such as the flavenoids found in grapefruit juice (Li et al. 2007). Future studies comparing intravenous administration of GTA to oral administration will be important to determine if efficacy can be improved by bypassing the digestive system.

The connection between NAA metabolism and lipid synthesis in the brain was first noted in the 1960s. D'Adamo and colleagues found that the acetate moiety of NAA is incorporated into brain lipids, and proposed that NAA acts to provide acetate for brain lipid synthesis (D'Adamo et al. 1968; D'Adamo and Yatsu 1966). Injecting carbon-14 and tritiumlabeled NAA into the brains of developing and adult rats, they found that the acetate moiety was readily incorporated into brain lipids during postnatal myelination. Approximately $1 / 3$ of the carbon incorporated into lipids during myelination was derived from the acetate group of NAA. This finding is consistent with the recent findings from our laboratory and the Ledeen laboratory that lipid synthesis is reduced by about $1 / 3$ in the brains of developing ASPA -/mice (Madhavarao et al. 2005) and tremor rats (Wang et al. 2009).

The present studies confirm earlier investigations indicating a role for NAA as an acetyl source in brain lipid synthesis, and show that NAA is likely to serve multiple developmental and neurochemical roles in the nervous system. We propose that the high concentration of NAA is a nervous system-specific mechanism for storing and transporting acetate to be used for acetyl coenzyme A synthesis, and subsequent acetylation reactions critical for brain development and function. A number of studies have indicated that production of NAA in neuronal mitochondria is somehow linked to energy metabolism in the brain (Patel and Clark 1979), and this role could involve the use of NAA as a storage and transport form of acetate. Importantly, NAA is probably a major source of acetate that is transported from the site of synthesis in neurons to the site of catalysis in oligodendrocytes where the free acetate can be reconverted to acetyl coenzyme A for lipid synthesis (Patel and Clark 1980) and protein acetylation reactions. This would allow neurons to regulate the rate at which acetate is supplied to their ensheathing oligodendrocytes.

The ASPA deficiency in the mouse knock-out model of Canavan disease (Aspa -/- mice) results in an $80 \%$ reduction in total brain acetate levels, as well as significant decreases in the levels of certain polar and non-polar lipids including cerebrosides during the period of postnatal myelination (Madhavarao et al. 2005). The decrease in brain lipid content has been verified in the tremor rat model of Canavan disease (Wang et al. 2009), and in the Nur7 ASPA-deficient mouse (Traka et al., 2008). However, further work with the Nur7 mouse suggested that disrupted myelin synthesis was not the only pathogenic mechanism involved in the etiology of the spongy degeneration associated with Canavan disease. Specifically, Nur7 ASPA-deficient mice were generated that were heterozygous for a null allele of the galactolipidsynthesizing enzyme UDP-galactose:ceramide galactosyltransferase (Cgt), which further reduced brain cerebroside content. Despite this further reduction in brain cerebroside content, the mice were not more severely affected than those harboring only homozygous Nur7 mutations in the Aspa gene.

These findings implicate other potential mechanisms in the pathophysiology of ASPA deficiency in addition to defective myelin synthesis. One aspect of the neuropathologies associated with ASPA deficiency that does not comport directly with disrupted myelination is the substantial brain and spinal cord vacuolation observed in gray matter, and sparing of many white matter areas (Surendran et al. 2005; Traka et al. 2008). The vacuolation appears between postnatal days 14 and 21 in the Nur7 ASPA-deficient mouse, which coincides with the peak of postnatal myelination. We have also observed vacuolation in many gray matter areas and sparing of specific white matter tracts in the adult tremor rat brain (unpublished observations). Recent studies on oligodendrocyte maturation have highlighted the important role of histone acetylation and deacetylation in the epigenetic control of cellular differentiation from oligodendrocyte precursor cells to mature oligodendrocytes (Copray et al. 2009; MacDonald and Roskams 2009; Ye et al. 2009). Because neurons transfer NAA to oligodendrocytes (Chakraborty et al. 2001), and oligodendrocytes strongly express ASPA (Klugmann et al. 2003; Madhavarao et al. 2004), it is likely that NAA-derived acetate is an important source of acetyl coenzyme A in oligodendrocytes for histone acetylation reactions that regulate chromatin structure and gene transcription. The finding that ASPA is expressed in the nuclei of oligodendrocytes, as well as in their cytoplasm (Hershfield et al. 2006), is consistent with this role for NAAderived acetate. The dramatic reduction in acetate availability in oligodendrocytes resulting from ASPA deficiency could impact histone acetyltransferase reactions required for epigenetic gene regulation. The resultant disruption of oligodendrocyte differentiation would explain the observed loss of mature oligodendrocytes in the cerebellum and brainstem of Nur7 ASPA-deficient mice (Traka et al. 2008).

In order for free acetate derived from NAA hydrolysis to be utilized, it must be enzymatically converted to acetyl coenzyme A. We found that acetyl coenzyme A synthase-1 
(AceCS1), which converts free acetate to acetyl coenzyme A, is present in the nuclei and cytoplasm of many oligodendrocytes in 18-day-old rats (Fig. 5). Further, AceCS1 protein expression was upregulated in neurons and oligodendrocytes in adult tremor rats as compared with wild-type controls (Figs. 6 and 7). Expression of AceCS1 in GTA-treated tremor rats was reduced relative to untreated tremor rats and was returned to near wild-type levels. AceCS1 is known to be involved in lipid synthesis (Luong et al. 2000) and has recently been shown to be involved in histone acetylation reactions necessary for cell differentiation (Wellen et al. 2009). The reduced substrate availability for AceCS1 could negatively impact histone acetylation critical for proper oligodendrocyte maturation (Copray et al. 2009; Kumar et al. 2009). It seems likely that ASPA deficiency leads to improper regulation of histone acetylation in developing oligodendrocytes, preventing normal differentiation and leading to oligodendrocyte cell death, dysmyelination, neuronal injury, and inflammation, possibly contributing to vacuole formation. It is noteworthy that GTA treatment also modestly reduced vacuole formation (see Fig. 8). One important conclusion that can be drawn from these observations is that NAA-derived acetate is not only involved in brain myelination but it may also be involved in gene regulation associated with cellular differentiation and brain development.

Another possible mechanism linking reduced acetyl coenzyme A availability and the neuropathologies in Canavan disease involves posttranslational acetylation of proteins in the endoplasmic reticulum, particularly in oligodendrocytes. Cells which have active protein secretory pathways through the endoplasmic reticulum, such as oligodendrocytes, are sensitive to disorders of protein mis-folding. Acetylation and deacetylation of nascent polypeptide chains in the endoplasmic reticulum secretory pathway of cells is required for stabilization and correct folding (Costantini et al. 2007; Spange et al. 2009). Acetyl coenzyme A is required for the acetyltransferase reactions involved in acetylation at lysine sites on newly synthesized proteins. The substantial drop in brain acetate levels that occur in ASPA deficiency could have a negative impact on protein folding and stabilization, thus targeting proteins for endoplasmic reticulum associated degradation (ERAD). In the ASPA knockout mouse, a severe loss of myelin basic protein and PLP/DM20 proteolipid proteins has been observed, combined with a decrease in myelinated fibers and perinuclear retention of myelin protein staining. These are clear indicators of an impairment in protein trafficking in oligodendrocytes (Kumar et al. 2009). Oligodendrocytes are highly susceptible to endoplasmic reticulum stress (ERS) associated with disruptions in protein synthesis and trafficking (Lin and Popko 2009). It is likely that the dramatic drop in NAAderived acetate in Canavan disease has a negative impact on the protein secretory pathway in oligodendrocytes. Because all of the potential pathogenic mechanisms involve reductions in acetate availability associated with the inability to deacetylate NAA, it is possible that GTA administration may provide needed substrate for acetyl coenzyme A synthesis required for all three cellular functions; fatty acid synthesis, nuclear histone acetylation, and endoplasmic reticulum protein acetylation.

In conclusion, the acetate precursor GTA improved motor performance and increased myelin galactocerebroside content in the tremor rat model of Canavan disease, without overt toxicity. GTA treatment also decreased brain vacuolation, and the improvements in motor performance were positively correlated with the reduced vacuolation. Additionally, GTA treatment returned the elevated AceCS1 expression levels in tremor rats to near control levels. None of the pathological consequences of ASPA deficiency were completely reversed by GTA administration, indicating that additional investigations and modifications to the treatment regimen will be necessary to further improve long-term outcomes. Nonetheless, acetate supplementation is a safe and promising treatment strategy for Canavan disease that is inexpensive and easy to administer. GTA-based acetate supplementation is a unique method for addressing dysmyelination in Canavan disease in particular, and possibly other disorders of myelination, or brain injury (Arun et al. 2010). Finally, the important role of NAA-derived acetate in brain development and myelination is further confirmed. Additional research will be required to determine the role of compromised nuclear histone acetylation and endoplasmic reticulum protein acetylation in the etiology of Canavan disease.

Acknowledgements This work was supported by grants from the NINDS/NIH (RO1/R56 grant NS39387), the Samueli Institute (Alexandria, VA), Jacob's Cure (New York, NY) and NTSAD (Boston, MA) to A.M.A.N. C.N.M. was supported by the Rosalind Poss Rosen Clinical Research Training Fellowship of the American Academy of Neurology Foundation co-sponsored by the Canavan Foundation. We are grateful to the National Bio Resource Project for the Rat in Japan (http://www.anim.med.kyoto-u.ac.jp/nbr/) for providing the Tremor rat strain (NBRP-Rat\#0015), and to Dr. James Garbern for providing antiASPA antibodies.

Open Access This article is distributed under the terms of the Creative Commons Attribution Noncommercial License which permits any noncommercial use, distribution, and reproduction in any medium, provided the original author(s) and source are credited.

\section{References}

Adachi M, Schneck L, Cara J, Volk BW (1973) Spongy degeneration of the central nervous system (van Bogaert and Bertrand type; Canavan's disease). A review. Human Pathol 4(3):331-347

Ariyannur PS, Moffett JR, Madhavarao CN, Arun P, Vishnu N, Jacobowitz D, Hallows WC, Denu JM, Namboodiri AM (2010) 
Nuclear-cytoplasmic localization of acetyl coenzyme A synthetase-1 in the rat brain. J Comp Neurol; epub ahead of print Arun P, Ariyannur PS, Moffett JR, Xing G, Hamilton K, Grunberg NE, Ives JA, Namboodiri AM (2010) Metabolic acetate therapy for the treatment of traumatic brain injury. J Neurotrauma 27:293-298

Bailey JW, Haymond MW, Miles JM (1991) Triacetin: a potential parenteral nutrient. J Parenter Enteral Nutr 15(1):32-36

Bailey JW, Barker RL, Karlstad MD (1992) Total parenteral nutrition with short- and long-chain triglycerides: triacetin improves nitrogen balance in rats. J Nutr 122(9):1823-1829

Baslow MH (1999) Molecular water pumps and the aetiology of Canavan disease: a case of the sorcerer's apprentice. J Inherit Metab Dis 22(2):99-101

Baslow MH (2003) Brain N-acetylaspartate as a molecular water pump and its role in the etiology of Canavan disease: a mechanistic explanation. J Mol Neurosci 21(3):185-190

Chakraborty G, Mekala P, Yahya D, Wu G, Ledeen RW (2001) Intraneuronal $\mathrm{N}$-acetylaspartate supplies acetyl groups for myelin lipid synthesis: evidence for myelin-associated aspartoacylase. J Neurochem 78(4):736-745

Copray S, Huynh JL, Sher F, Casaccia-Bonnefil P, Boddeke E (2009) Epigenetic mechanisms facilitating oligodendrocyte development, maturation, and aging. Glia 57(15):1579-1587

Costantini C, Ko MH, Jonas MC, Puglielli L (2007) A reversible form of lysine acetylation in the ER and Golgi lumen controls the molecular stabilization of BACE1. Biochem J 407(3):383-395

D'Adamo AF Jr, Yatsu FM (1966) Acetate metabolism in the nervous system. N-acetyl-L-aspartic acid and the biosynthesis of brain lipids. J Neurochem 13(10):961-965

D'Adamo AF Jr, Gidez LI, Yatsu FM (1968) Acetyl transport mechanisms. Involvement of $\mathrm{N}$-acetyl aspartic acid in de novo fatty acid biosynthesis in the developing rat brain. Exp Brain Res 5(4):267-273

Elliott BM, Faraday MM, Phillips JM, Grunberg NE (2004) Effects of nicotine on elevated plus maze and locomotor activity in male and female adolescent and adult rats. Pharmacol Biochem Behav 77(1):21-28

Hallows WC, Lee S, Denu JM (2006) Sirtuins deacetylate and activate mammalian acetyl-CoA synthetases. Proc Natl Acad Sci USA 103(27):10230-10235

Hershfield J, Madhavarao CN, Moffett JR, Benjamins JA, Garbern JY, Namboodiri MA (2006) Aspartoacylase is a regulated nuclearcytoplasmic enzyme. FASEB J 20(12):2139-2141

Janson C, McPhee S, Bilaniuk L, Haselgrove J, Testaiuti M, Freese A, Wang DJ, Shera D, Hurh P, Rupin J, Saslow E, Goldfarb O, Goldberg M, Larijani G, Sharrar W, Liouterman L, Camp A, Kolodny E, Samulski J, Leone P (2002) Clinical protocol. Gene therapy of Canavan disease: AAV-2 vector for neurosurgical delivery of aspartoacylase gene (ASPA) to the human brain. Hum Gene Ther 13(11):1391-1412

Kitada K, Akimitsu T, Shigematsu Y, Kondo A, Maihara T, Yokoi N, Kuramoto T, Sasa M, Serikawa T (2000) Accumulation of Nacetyl-L-aspartate in the brain of the tremor rat, a mutant exhibiting absence-like seizure and spongiform degeneration in the central nervous system. J Neurochem 74(6):2512-2519

Klugmann M, Symes CW, Klaussner BK, Leichtlein CB, Serikawa T, Young D, During MJ (2003) Identification and distribution of aspartoacylase in the postnatal rat brain. NeuroReport 14 (14): $1837-1840$

Klugmann M, Leichtlein CB, Symes CW, Serikawa T, Young D, During MJ (2005) Restoration of aspartoacylase activity in CNS neurons does not ameliorate motor deficits and demyelination in a model of Canavan disease. Mol Ther 11(5):745753

Kumar S, Biancotti JC, Matalon R, de Vellis J (2009) Lack of aspartoacylase activity disrupts survival and differentiation of neural progenitors and oligodendrocytes in a mouse model of Canavan disease. J Neurosci Res 87(15):3415-3427

Kvittingen EA, Guldal G, Borsting S, Skalpe IO, Stokke O, Jellum E (1986) $\mathrm{N}$-acetylaspartic aciduria in a child with a progressive cerebral atrophy. Clin Chim Acta 158(3):217-227

Leone P, Janson CG, Bilaniuk L, Wang Z, Sorgi F, Huang L, Matalon R, Kaul R, Zeng Z, Freese A, McPhee SW, Mee E, During MJ, Bilianuk L (2000) Aspartoacylase gene transfer to the mammalian central nervous system with therapeutic implications for Canavan disease. Ann Neurol 48(1):27-38

Li P, Callery PS, Gan LS, Balani SK (2007) Esterase inhibition by grapefruit juice flavonoids leading to a new drug interaction. Drug Metab Dispos 35(7):1203-1208

Lin W, Popko B (2009) Endoplasmic reticulum stress in disorders of myelinating cells. Nat Neurosci 12(4):379-385

Luong A, Hannah VC, Brown MS, Goldstein JL (2000) Molecular characterization of human acetyl-CoA synthetase, an enzyme regulated by sterol regulatory element-binding proteins. J Biol Chem 275(34):26458-26466

MacDonald JL, Roskams AJ (2009) Epigenetic regulation of nervous system development by DNA methylation and histone deacetylation. Prog Neurobiol 88(3):170-183

Madhavarao CN, Moffett JR, Moore RA, Viola RE, Namboodiri MA, Jacobowitz DM (2004) Immunohistochemical localization of aspartoacylase in the rat central nervous system. J Comp Neurol 472(3):318-329

Madhavarao CN, Arun P, Moffett JR, Szucs S, Surendran S, Matalon R, Garbern J, Hristova D, Johnson A, Jiang W, Namboodiri MA (2005) Defective N-acetylaspartate catabolism reduces brain acetate levels and myelin lipid synthesis in Canavan's disease. Proc Natl Acad Sci USA 102(14):5221-5226

Madhavarao CN, Arun P, Anikster Y, Mog SR, Staretz-Chacham O, Moffett JR, Grunberg NE, Gahl WA, Namboodiri AM (2009) Glyceryl triacetate for Canavan disease: A low-dose trial in infants and evaluation of a higher dose for toxicity in the tremor rat model. J Inherit Metab Dis 32:640-650

Matalon R, Michals K, Sebesta D, Deanching M, Gashkoff P, Casanova J (1988) Aspartoacylase deficiency and Nacetylaspartic aciduria in patients with canavan disease. Am J Med Genet 29:463-471

Matalon R, Rady PL, Platt KA, Skinner HB, Quast MJ, Campbell GA, Matalon K, Ceci JD, Tyring SK, Nehls M, Surendran S, Wei J, Ezell EL, Szucs S (2000) Knock-out mouse for Canavan disease: a model for gene transfer to the central nervous system. J Gene Med 2(3):165-175

Mathew R, Arun P, Madhavarao C, Moffett J, Namboodiri A (2005) Progress toward acetate supplementation therapy for Canavan disease: Glyceryl triacetate administration increases acetate, but not N-acetylaspartate levels in brain. J Pharmacol Exp Ther 315 (1):297-303

McPhee SW, Francis J, Janson CG, Serikawa T, Hyland K, Ong EO, Raghavan SS, Freese A, Leone P (2005) Effects of AAV2-mediated aspartoacylase gene transfer in the tremor rat model of Canavan disease. Brain Res Mol Brain Res 135(12):112-121

Moffett JR, Ross B, Arun P, Madhavarao CN, Namboodiri AM (2007) N-Acetylaspartate in the CNS: From neurodiagnostics to neurobiology. Prog Neurobiol 81(2):89-131

Norton WT, Poduslo SE (1973) Myelination in rat brain: method of myelin isolation. J Neurochem 21(4):749-757

Patel TB, Clark JB (1979) Synthesis of N-acetyl-L-aspartate by rat brain mitochondria and its involvement in mitochondrial/cytosolic carbon transport. Biochem J 184(3):539-546

Patel TB, Clark JB (1980) Lipogenesis in the brain of suckling rats. Studies on the mechansim of mitochondrial-cytosolic carbon transfer. Biochem J 188(1):163-168 
Spange S, Wagner T, Heinzel T, Kramer OH (2009) Acetylation of non-histone proteins modulates cellular signalling at multiple levels. Int J Biochem Cell Biol 41(1):185-198

Surendran S, Campbell GA, Tyring SK, Matalon R (2005) Aspartoacylase gene knockout results in severe vacuolation in the white matter and gray matter of the spinal cord in the mouse. Neurobiol Dis 18(2):385-389

Traka M, Wollmann RL, Cerda SR, Dugas J, Barres BA, Popko B (2008) Nur7 is a nonsense mutation in the mouse aspartoacylase gene that causes spongy degeneration of the CNS. J Neurosci 28 (45):11537-11549
Wang J, Leone P, Wu G, Francis JS, Li H, Jain MR, Serikawa T, Ledeen RW (2009) Myelin lipid abnormalities in the aspartoacylasedeficient tremor rat. Neurochem Res 34(1):138-148

Wellen KE, Hatzivassiliou G, Sachdeva UM, Bui TV, Cross JR, Thompson CB (2009) ATP-citrate lyase links cellular metabolism to histone acetylation. Science 324(5930):1076-1080

Ye F, Chen Y, Hoang T, Montgomery RL, Zhao XH, Bu H, Hu T, Taketo MM, van Es JH, Clevers H, Hsieh J, Bassel-Duby R, Olson EN, Lu QR (2009) HDAC1 and HDAC2 regulate oligodendrocyte differentiation by disrupting the beta-cateninTCF interaction. Nat Neurosci 12(7):829-838 